\title{
Characterization Method of Ionization Chamber Type Detectors
}

\author{
L. Pibida \\ R. Minniti \\ M. McCord
}

This publication is available free of charge from: https://doi.org/10.6028/NIST.TN.2204 
NIST Technical Note 2204

\title{
Characterization Method of Ionization Chamber Type Detectors
}

\author{
L. Pibida \\ R. Minniti \\ M. McCord \\ Radiation Physics Division \\ Physical Measurement Laboratory
}

This publication is available free of charge from:

https://doi.org/10.6028/NIST.TN.2204

February 2022

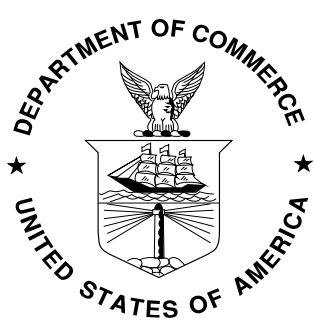

U.S. Department of Commerce Gina M. Raimondo, Secretary

National Institute of Standards and Technology James K. Olthoff, Performing the Non-Exclusive Functions and Duties of the Under Secretary of Commerce for Standards and Technology \& Director, National Institute of Standards and Technology 
Certain commercial entities, equipment, or materials may be identified in this document in order to describe an experimental procedure or concept adequately. Such identification is not intended to imply recommendation or endorsement by the National Institute of Standards and Technology, nor is it intended to imply that the entities, materials, or equipment are necessarily the best available for the purpose.

National Institute of Standards and Technology Technical Note 2204 Natl. Inst. Stand. Technol. Tech. Note 2204, 26 pages (February 2022) CODEN: NTNOEF

This publication is available free of charge from: https://doi.org/10.6028/NIST.TN.2204 


\begin{abstract}
A wide variability in accuracy exists among commercial radiation detection instruments used to measure exposure rate or ambient dose equivalent rate. These instruments are used to measure both the radiation background and the radiation field produced by radioactive sources that are used to test other types of radiation detection systems against different consensus document standards. These instruments are used as reference instruments. This document provides information and recommendations on how to characterize ionization chambers including high pressure ionization chambers (HPIC) and unsealed standard ionization chambers.
\end{abstract}

\title{
Key words
}

Calculations, characterization, ionization chamber, measurements. 


\section{Table of Contents}

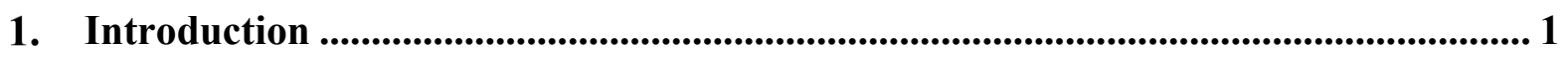

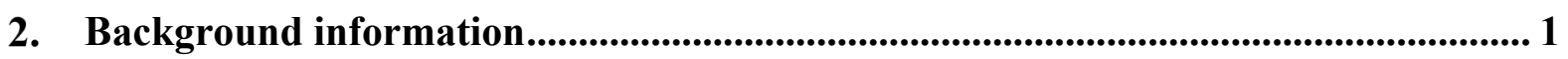

3. Proposed detector calibration procedure ........................................................................ 4

4. Transferring calibrations between instruments ............................................................. 6

5. Instrument characterization using exposure rate calculations ..................................... 7

6. Uncertainty calculations..................................................................................................... 10

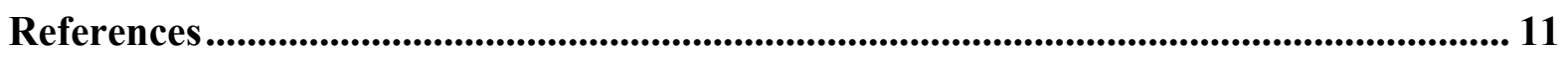

Appendix A: Example on how to apply the calculations and comparison with measurements

\section{List of Tables}

Table 1: List of reference calibration conditions

Table 2: Values of the mass energy-transfer, mass energy-absorption, and mass attenuation coefficients for air. The $18 \mathrm{~K}$ in the table refers to the photoelectric absorption $\mathrm{K}$ edge......... 9

Table 3: Source activities used for measurements ........................................................... 14

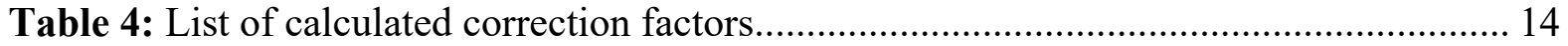

Table 5: List of measured and corrected exposure rate values. The correction factors are listed in Table 4 Uncertainties are $\mathrm{k}=1$...................................................................... 15

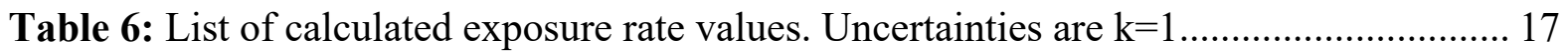

Table 7: Percent differences of the measured exposure rate values to the calculated values. Uncertainties are $\mathrm{k}=1$.

Table 8: Calculated buildup factors for medical radionuclides in $8 \mathrm{~cm}$ of PMMA.

Uncertainties are $\mathrm{k}=1$.

Table 9: List of NIST instrument correction factors, the correction factors provided in instrument manual for ANL instrument and the transfer values using Eq. 3.

Table 10: Exposure rate calculated using Eq. 8, measured using NIST and ANL instruments for NT sources. The uncertainties for these values are approximately equal to $20 \%$. 20

\section{List of Figures}

Fig. 1: Correction factor for the instrument from data reported in the instrument manual and from measurements made in the NIST reference radiation beam. The polynomial fits to the data from the instrument manual and the NIST measurements are also shown. For the NIST measurements the uncertainties in the $y$-axis are smaller than the size of the symbol............ 4

Fig. 2: Measured and calculated exposure rate values for bare sources from Table 4......... 16 Fig. 3: Measured and calculated buildup factors. The black squares are the values obtained from Ref. [31] for water, the red circles are the calculated values for the sources surrounded by PMMA using the mean free path approximation and the blue triangles are measured values when surrounded by the PMMA shielding. 
Fig. 4: The measured and calculated exposure rate values when shielded using PMMA. The black squares represent the measured values, the red circles are the calculated values corrected using the buildup factors in Ref. [31] and the blue triangles are the calculated values without applying the buildup factors. 


\section{Introduction}

A wide variability in accuracy exists among commercial radiation detection instruments used to measure exposure rate or ambient dose equivalent rate. These instruments are used to measure both the radiation background and the radiation field produced by radioactive sources that are used to test other types of radiation detection systems against different consensus document standards. These instruments are used as reference instruments.

Currently, the American National Standards Institute/Institute of Electrical and Electronics Engineers (ANSI/IEEE) and the International Electrotechnical Commission (IEC) each have eight published standards for homeland security applications encompassing a myriad of detection equipment types, see Refs. [1-16]. Although some measurement systems identify radionuclides, all systems measure the magnitude of the radiation field in some form (e.g., $\mu \mathrm{R} / \mathrm{h}, \mu \mathrm{Sv} / \mathrm{h}$, counts/s, unit-less). Most radiation fields specified in the ANSI/IEEE and IEC standards have quite low dose rates, ranging from $0.05 \mu \mathrm{Sv} / \mathrm{h}$ to $1.0 \mu \mathrm{Sv} / \mathrm{h}$ above background over a large energy range from $60 \mathrm{keV}$ to $2.6 \mathrm{MeV}$. The low energy limit corresponds to the detection effectiveness due to typical low energy cut-off of detectors and the upper range to detector response.

Due to the radiation fields being so low in intensity, the uncertainty of the measurements made with these instruments can be potentially quite large. In addition, the energy response function of these instruments as a function of photon energy can vary significantly over the energy range of interest. Therefore, these types of instruments need to be characterized in terms of their energy response so that suitable correction factors can be determined to account for changes in the energy response. This energy characterization is essential when using these detectors to measure the radiation field from different radionuclides used to test radiation detection instruments.

To achieve consistency across different testing laboratories in setting up radiation fields for testing of radiation detection instruments, it is important that the reference instruments used to determine the radiation fields are well characterized in terms of their energy response. This document provides information and recommendations on how to characterize ionization chambers, including high pressure ionization chambers (HPICs) and unsealed standard ionization chambers.

\section{Background information}

NIST owns an HPIC model GE RSS-131ER ${ }^{1}$ with the following characteristics: the detector is encased in a $31 \mathrm{~cm} \times 31 \mathrm{~cm} \times 36 \mathrm{~cm}$ aluminum enclosure, this unit contains $2533 \mathrm{kPa}(25$ atmospheres) $)^{2}$ of argon in a $25.4 \mathrm{~cm}$ diameter stainless steel sphere (wall thickness of $3.2 \mathrm{~mm}$ )

\footnotetext{
${ }^{1}$ Certain commercial equipment, instruments, or materials are identified in this paper to foster understanding. Such identification does not imply recommendation or endorsement by the National Institute of Standards and Technology, nor does it imply that the materials or equipment identified are necessarily the best available for the purpose.

${ }^{2}$ NIST does not endorse the use of non-SI units. This paper uses non-SI units because it addresses the requirements listed in the ANSI/IEEE published standards.
} 
and has the capability to measure exposure rates from background levels up to $100 \mathrm{R} / \mathrm{h}$. The HPIC measures in units of Roentgen per hour 2, a special unit quantifying exposure rate as opposed to measuring in the international system of units (SI). In the spirit of reproducing the exact values measured as read from the instrument, all units listed hereafter will be as read out directly by the HPIC. This instrument can operate independently (not connected to a PC) in a range of different surroundings, and data files (consisting of time stamped exposure rate or count rate data) produced by the HPIC may be later downloaded to a computer after the measurements are completed. The acquired data may also be observed in real time if the HPIC is connected to an external computer and downloaded as a "csv" file. From the energy response curve given in the manual, the detector's low-energy cutoff is approximately $50 \mathrm{keV}$, where the response is $\approx 10 \%$ of its relatively constant value between $300 \mathrm{keV}$ and $10 \mathrm{MeV}$.

The HPIC was characterized using the following NIST reference beams (i.e., parallel beams), see Ref. [21] for additional information:

$$
\begin{aligned}
& \text { - }{ }^{137} \mathrm{Cs} \\
& \text { - }{ }^{60} \mathrm{Co} \\
& \text { - } \quad \text { X-ray beams }
\end{aligned}
$$

The ${ }^{137} \mathrm{Cs}$ beams produced exposure rates of $0.286 \mathrm{mR} / \mathrm{h}, 7.146 \mathrm{mR} / \mathrm{h}, 42.85 \mathrm{mR} / \mathrm{h}$, and $127.4 \mathrm{mR} / \mathrm{h}$ with associated relative expanded uncertainties of $1 \%(k=2)$ Ref. [22] and for source-to-detector (detector center) distances of $300 \mathrm{~cm}$. For a fixed exposure rate, the differences in the measured mean values between sets of 10 readings were less than $0.5 \%$. The instrument readings were higher than the reference values by $2.6 \%$ (at $0.286 \mathrm{mR} / \mathrm{h}$ ), $4.3 \%$ (at $7.146 \mathrm{mR} / \mathrm{h}$ ), $2.5 \%$ (at $127.4 \mathrm{mR} / \mathrm{h}$ ), and $1.9 \%$ (at $42.85 \mathrm{mR} / \mathrm{h})^{2}$.

For the ${ }^{60} \mathrm{Co}$ beam, fields of $42.85 \mathrm{mR} / \mathrm{h}$ and $102.2 \mathrm{mR} / \mathrm{h}$ (also with uncertainties of $1 \%(k=$ 2)) were generated with the same beam by moving the detector to positions at $300 \mathrm{~cm}$ and $195 \mathrm{~cm}$, respectively. Repeatability among sets of 10 readings was less than $0.1 \%$. For this source, the instrument readings were higher than the reference value by $2.3 \%$ (at $102.2 \mathrm{mR} / \mathrm{h}$ ) and $1.9 \%$ (at $42.85 \mathrm{mR} / \mathrm{h}$ ). For the relative instrument response curve, an average energy of $1252.993 \mathrm{keV}$ (weighted by the emission probabilities of the two gamma-ray lines) was used to display the instrument response to ${ }^{60} \mathrm{Co}$. Weighted averages were used to combine data for one radionuclide at different exposure rates.

Calibration measurements were also performed with x-ray beams, yielding effective energies of $60 \mathrm{keV}$ (LK70 at $141 \mathrm{mR} / \mathrm{h}$ and $271 \mathrm{mR} / \mathrm{h}), 65 \mathrm{keV}(\mathrm{NS} 80$ at $719 \mathrm{mR} / \mathrm{h}), 83 \mathrm{keV}(\mathrm{NS} 100$ at $424 \mathrm{mR} / \mathrm{h}), 87 \mathrm{keV}(\mathrm{LK} 100$ at $181 \mathrm{mR} / \mathrm{h}$ and $357 \mathrm{mR} / \mathrm{h}), 109 \mathrm{keV}(\mathrm{LK} 125$ at $255 \mathrm{mR} / \mathrm{h}$ ), $149 \mathrm{keV}$ (LK170 at $216 \mathrm{mR} / \mathrm{h}$ ), and $211 \mathrm{keV}$ (LK240 at $424 \mathrm{mR} / \mathrm{h}$ ) Refs. [17, 18]. The energy spreads in the $\mathrm{x}$-ray beams (as measured by the full width at half maximum) ranged from $18 \%$ to $32 \%$ from the effective energies, and the uncertainties in the calibrated rates spanned from $1.1 \%$ to $2.2 \%(k=2)$. No strong exposure rate dependence was observed. For the beams at $60 \mathrm{keV}$ and $87 \mathrm{keV}$, due to constraints in the experimental setup, the calibrated exposure rate was measured relative to the front face of the detector. These values were corrected using the 
inverse square law for the dependence of the exposure rate with the source-to-detector distance to estimate the value at the center of the detector. Measurements both at the front face and center of the detector were performed on a separate $\mathrm{x}$-ray range to investigate the potential deviations from the inverse square law. The maximum observed difference due to scaling one of these rates and comparing to its respective measured value was $1.6 \%$, and most differences were much smaller. Although for the higher energies, the values from the instrument manual agreed to within a few percent of the NIST instrument response calibrations, the values at low energies were somewhat larger, ranging from $7 \%$ to $24 \%$ larger than the NIST calibration values at the respective energies.

The energy response of the instrument is shown in Fig. 1 and as it can clearly be observed, the energy dependence is far from having a constant value. The largest energy dependence is seen for lower energies reaching differences of up to $60 \%$ relative to the response for ${ }^{137} \mathrm{Cs}$. Because of this strong energy dependence, suitable correction factors need to be applied to all measured exposure rate data to account for any differences in the energy response of the measuring instrument. Applying suitable energy corrections is critical to ensure that the exposure rate of the radiation fields used for testing detectors is measured correctly. So, for example if one were to measure the exposure rate of a radiation field that has an energy spectrum that resembles that of an LK170 x-ray beam quality which has an average energy of $140 \mathrm{keV}$, as seen in the red curve Fig. 1, a correction factor of about 1.3 would need to be applied to the reading to obtain the correct value of the exposure rate.

The accuracy of the correction factors provided in the HPIC manual were compared against seven reference beams at the National Institute of Standards and Technology (NIST), using ${ }^{137} \mathrm{Cs},{ }^{60} \mathrm{Co}$, and $\mathrm{x}$-rays at different exposure rates. For most beam quality and calibration rates, multiple sets of 10 readings were recorded, as well as their respective means and standard deviations. The weighted average of these values was calculated, and its uncertainty was combined with the uncertainty in the beam calibration at the specified rate. Then for each beam energy, the mean and standard deviation among the various rates were determined using the weighted average at each rate. The values provided in the manual as well as those measured at NIST are shown in Fig. 1. As it can be clearly seen, the generic energy response provided in the HPIC manual differs significantly from the actual energy response of the unit that was calibrated at NIST. This implies that the generic curve shown in Fig. 1 cannot be used as a calibration curve for all units of the same model instrument. Instead, every single unit needs to be calibrated independently to ensure that it will measure accurately, and that the measurement provided by the instrument is traceable to the National standard. Only in this way one can ensure that all instruments of the same model measure in exactly the same way and that the use of these instruments for either safety or security applications can be achieved. 


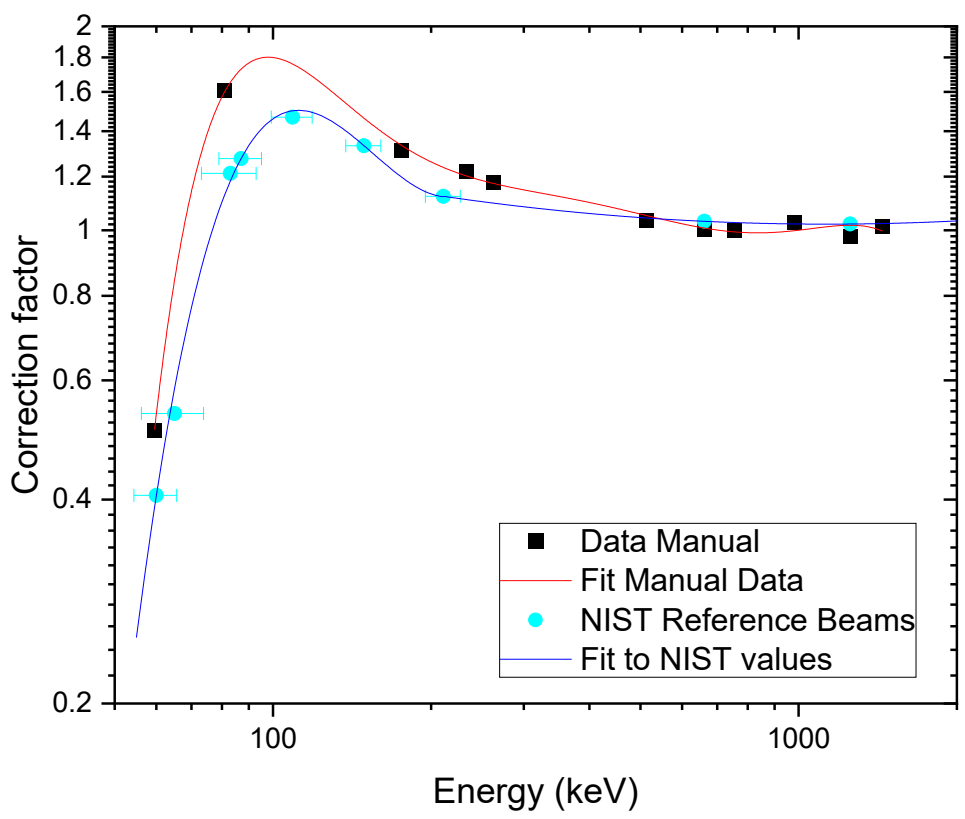

Fig. 1: Correction factor for the instrument from data reported in the instrument manual and from measurements made in the NIST reference radiation beam. The polynomial fits to the data from the instrument manual and the NIST measurements are also shown. For the NIST measurements the uncertainties in the y-axis are smaller than the size of the symbol.

\section{Proposed detector calibration procedure}

In order to fully characterize an ionization chamber, it is best to calibrate the chamber in radiation fields that closely match the radiation fields in which the instruments may be later used. For this purpose, ionization chambers are calibrated with selected beam qualities that range from the low $\mathrm{keV}$ range for $\mathrm{x}$-rays up to the average energy of $1.25 \mathrm{MeV}$ for ${ }^{60} \mathrm{Co}$. Assuming that the instrument response is relatively independent of the exposure rate of the radiation field, a similar exposure rate value shall be used for all beam qualities to calibrate the detector. Under these conditions the following reference beams are recommended to fully characterize the instruments:

- ${ }^{137} \mathrm{Cs}$

- ${ }^{60} \mathrm{Co}$

- $x$-ray beams with the following average energies: $60 \mathrm{keV}$ (LK70), $65 \mathrm{keV}$ (NS80), $83 \mathrm{keV}$ (NS100), $109 \mathrm{keV}$ (LK125), $149 \mathrm{keV}$ (LK170), and $211 \mathrm{keV}$ (LK240). Similar energies may be used provided they have a narrow energy spectrum Ref. [18]. It is best if at a minimum the instruments are characterized with the beam qualities proposed here. 
The instruments shall be calibrated in the orientations in which they are used routinely. Additional considerations in the measurement setup include the following:

1) the distance of the instrument should be far enough from the radiation source (e.g., at least 5 detector diameters) to limit any non-homogeneity in the field being measured,

2) the field strength is sufficiently high above background level to have a stable reading,

3) use integration times are sufficiently long for better statistics (i.e., low statistical fluctuations),

4) the reference point in the instrument shall be identified (i.e., either from the instrument markings or described in the instrument manual) and used for all measurements,

5) for each photon energy and field strength collect at least 10 independent readings.

Ideally, calibrations should be performed at the environmental reference conditions listed in Table 1.

Table 1: List of reference calibration conditions

\begin{tabular}{|l|l|}
\hline Variable & Reference value \\
\hline Air pressure, $\mathrm{p}_{0}$ & $101.3 \mathrm{kPa}$ \\
\hline Air temperature, $\mathrm{T}_{0}$ & $293.15 \mathrm{~K}$ \\
\hline Relative humidity, $\mathrm{h}_{0}$ & $65 \%$ \\
\hline
\end{tabular}

For chambers that are unsealed (open to the atmosphere), if the temperature and pressure are different than those listed in Table 1, the instrument readings $M_{i}$ are normalized to the reference conditions listed in Table 1 by applying a correction factor $C_{T, p}$ as shown in the equations below:

$$
\begin{aligned}
& M=M_{i} \times C_{T, p} \times C_{h} \\
& C_{T, p}=\frac{p_{0} \times T}{p \times T_{0}}
\end{aligned}
$$

where:

$M_{i} \quad$ Measured exposure readings at the actual values of pressure $\mathrm{p}$, temperature $\mathrm{T}$ and humidity $\mathrm{h}$.

$M \quad$ Exposure readings normalized to the reference conditions of $\mathrm{T}_{0}, \mathrm{p}_{0}$, and $\mathrm{h}_{0}$ listed in Table 1

$C_{T, p} \quad$ Correction factor given in Eq. 2 used to normalize the exposure readings to the reference temperature and pressure conditions listed in Table 1. 
$C_{h} \quad$ Correction factor for any difference in relative humidity between the reference calibration conditions and conditions during measurement. The value of $C_{h}$ is determined from an empirical relationship between the response of ionization chambers as a function of relative humidity Refs. [19, 20]. The magnitude of this correction factor is usually small, and it is assumed that $C_{h}=1$ for the range of relative humidity generally encountered.

Note that some types of ionization chambers automatically correct their readings to account for temperature and/or pressure deviations from the reference conditions listed in Table 1 (i.e., temperature/ pressure compensation), obviating the need for further correction, provided that the compensation is to the reference calibration conditions listed in Table 1. Also, note that a temperature and pressure correction is not needed for chambers that are sealed such as the case of pressurized chambers.

It is recommended that ionization chamber calibrations be performed by laboratories or calibration facilities that are accredited by accreditation organizations such as National Voluntary Laboratory Accreditation Program (NVLAP), American Association for Laboratory Accreditation (A2LA) or equivalent, or at a minimum by calibration facilities that can demonstrate that their measurements are traceable to the National standard held by NIST. Alternatively, ionization chambers can be sent to National Metrology Institutes around the world similar to NIST.

\section{Transferring calibrations between instruments}

If radioactive sources are available such that their activities are traceable to a National Metrology Institute (e.g., NIST) and a calibrated chamber is also available, then it is possible to perform a cross calibration or calibration transfer to a second radiation measuring instrument. This is achieved by measuring the exposure rate at a given distance from the certified source with the calibrated instrument in a well-designed geometry and location. This becomes the reference instrument. Several sources emitting a single (or close to single) gamma-ray line will be needed to cover the entire energy range, mainly from approximately $60 \mathrm{keV}$ to $1253 \mathrm{keV}$. These sources include: ${ }^{57} \mathrm{Co},{ }^{60} \mathrm{Co},{ }^{51} \mathrm{Cr},{ }^{54} \mathrm{Mn},{ }^{65} \mathrm{Zn},{ }^{85} \mathrm{Sr},{ }^{95} \mathrm{Zr}$, ${ }^{109} \mathrm{Cd}$, ${ }^{137} \mathrm{Cs},{ }^{141} \mathrm{Ce},{ }^{170} \mathrm{Tm},{ }^{203} \mathrm{Hg},{ }^{241} \mathrm{Am}$.

The exposure rate (or dose rate), $M_{\text {Ref }}\left(E_{i}\right)$ for each source, displayed by the reference instrument should be recorded. This becomes the reference exposure rate measurement. After determining the exposure rate of the reference instrument at a given distance, the secondary instrument shall be placed in the same location where the reference instrument was placed to determine the exposure rate. In reproducing the same geometry and location, measurements using the secondary chamber are performed under the same scattering conditions as those performed using the reference instrument. The exposure rate (or dose rate), $M_{\sec }\left(E_{i}\right)$, displayed by the secondary instrument should be recorded. From these measurements a calibration factor for the secondary instrument, $N_{\sec }\left(E_{i}\right)$, can be determined as the ratio of the exposure rate measured by the reference instrument to the exposure rate measured using the secondary instrument. In this way a calibration factor can be obtained for each gamma-ray energy given by the expression below: 


$$
N_{s e c}\left(E_{i}\right)=\frac{M_{R e f}\left(E_{i}\right)}{M_{s e c}\left(E_{i}\right)}
$$

In doing these types of cross transfer calibrations, the secondary chamber should be calibrated in the direction in which it is used routinely. The reference point in the instrument should be identified and used for all measurements.

\section{Instrument characterization using exposure rate calculations}

If radioactive sources are available such that only their activities (and not dose rates) are traceable to a National Metrology Institute (e.g., NIST), then it is possible to perform an instrument characterization by calculating the exposure rates produced by the sources.

The proposed method assumes a point source in air, and it does not account for build-up in air. The low-energy cut-off (i.e., the minimum photon energy included in the calculations), $\delta$, used for the calculations shall be $40 \mathrm{keV}$, and for practical purposes only photon emissions with a probability larger than $0.5 \%$ shall be included in the calculation.

For a point source in vacuum, the fluence rate $\dot{\Phi}_{i}$ of photons with energy $E_{i}$ at a radial distance $r$ is simply $A P_{i} /\left(4 \pi r^{2}\right)$, where $A$ is the source activity, and $P_{i}$ is the probability per disintegration that a photon of energy $E_{i}$ is emitted. Assuming charged-particle equilibrium, the air-kerma rate $\dot{K}_{i}$ from photons of energy $E_{i}$ is then $\dot{K}_{i}=\dot{\Phi} E_{i} \frac{\mu_{t r}\left(E_{i}\right)}{\rho_{\text {air }}}$, where $\frac{\mu_{t r}\left(E_{i}\right)}{\rho_{\text {air }}}$ is the mass energytransfer coefficient for air and $\rho_{\text {air }}$ is the density of air Ref. [23] .

NOTE: The source activity provided in calibration source certificates is generally the value of the activity placed inside the source encapsulation.

In general, for a point source in vacuum emitting photons of more than one energy, the airkerma rate is obtained by summing over all photon energies as follows:

$$
\dot{K}_{\delta}=\sum_{i} \frac{A P_{i} E_{i}}{4 \pi r^{2}} \frac{\mu_{t r}\left(E_{i}\right)}{\rho_{\text {air }}}
$$

Now consider the point source surrounded by spherical shell(s) of encapsulating material in an infinite air medium. Each encapsulation material surrounding the source will have a thickness $z_{j}$ and a density $\rho_{j}$. The attenuation of the photon beam from any material surrounding the source and the column of air between the source and the point of detection can be accounted for by using the following estimate of the air-kerma rate at a radial distance $r$ :

$$
\dot{K}_{\delta}=\frac{A}{4 \pi r^{2}} \sum_{i} P_{i} E_{i} \frac{\mu_{t r}\left(E_{i}\right)}{\rho_{\text {air }}} \exp \left[-\sum_{j} \frac{\mu_{j}\left(E_{i}\right)}{\rho_{j}} \rho_{j} z_{j}\right] \exp \left[-\frac{\mu_{\text {air }}\left(E_{i}\right)}{\rho_{\text {air }}} \rho_{\text {air }} r\right]
$$

where $\mu_{j} / \rho_{j}$ is the mass attenuation coefficient for the encapsulating-layer material of thickness $z_{j}$ and density $\rho_{j}$, and $\mu_{\text {air } / / \rho_{\text {air }}}$ is that for air. Note that in Eq. 5 there are two exponentials. The first one accounts for the attenuation of all the materials surrounding the source while the second exponential accounts for the attenuation of the air column. 
The relationship between the radiation quantities of exposure $X$ (units of R) and air-kerma $K$ (units of Gy) is given by

$$
K=X\left(2.58 \times 10^{-4}\right)\left(\frac{W}{e}\right)\left(\frac{1}{1-g}\right)
$$

where $W / e$ is the mean energy expended in dry air by electrons per ion pair formed (equal to $33.97 \mathrm{~J} / \mathrm{C}$ ) Ref. [27], and $g$ is the mean fraction of the initial kinetic energy of secondary electrons liberated by photons that are lost through radioactive processes in air. The SI unit of exposure is the coulomb per kilogram $(\mathrm{C} / \mathrm{kg})$; the special unit of exposure, the roentgen $(\mathrm{R})$, is equal to exactly $2.58 \times 10^{-4} \mathrm{C} / \mathrm{kg}$.

The mass energy-absorption in air is defined as

$$
\mu_{e n}\left(E_{i}\right)=(1-g) \mu_{t r}\left(E_{i}\right)
$$

and its values are listed in Table 2.

From Eqs. 5, 6 and 7 an expression for the exposure rate, $\dot{X}$, can be easily derived for the practical case of an encapsulated source in air as

$$
\dot{X}_{\delta}=\frac{114.1 A}{4 \pi r^{2}} \sum_{i} P_{i} E_{i} \frac{\mu_{e n}\left(E_{i}\right)}{\rho_{\text {air }}} \exp \left[-\sum_{j} \frac{\mu_{j}\left(E_{i}\right)}{\rho_{j}} z_{j} \rho_{j}\right] \exp \left[-\frac{\mu_{\text {air }}\left(E_{i}\right)}{\rho_{\text {air }}} r \rho_{\text {air }}\right]
$$

To ensure that all testing laboratories obtain a consistent calculated value of the ambient dose equivalent rate, the different coefficients and values for the different quantities used in the equations above shall only be taken from the following references:

- $\quad \mu_{j} / \rho_{j}$ and $\rho_{j}$ shall be obtained from the $X C O M$ database, see Ref. [24].

- $\quad P_{i}$ shall be obtained from Ref. [25]; if a given radionuclide is not listed Ref. [25], then Ref. [26] shall be used. For radionuclides with long decay chains, the values for the probabilities per disintegration used should be those in equilibrium.

- The $\mu_{\mathrm{en} /} \rho_{\text {air }}$ and $\mu_{\text {air } /} \rho_{\text {air values are given here in Table } 2 .}$

- The density of air shall be $\rho_{\text {air }}=0.0012 \mathrm{~g} / \mathrm{cm}^{3}$.

- The cut-off energy, $\delta$, used for the calculations shall be $40 \mathrm{keV}$.

- All photon emissions with a probability larger than $0.5 \%$ shall be included in the calculation.

This method assumes that the sources used have small or negligible self-attenuation. This means that the dimensions and/or density of the source active material are such that the attenuation within the source is negligible. Appropriate corrections to Eq. 8 shall be applied to account for source self-attenuation for the case of large and/or dense sources. 
An additional contribution to the exposure rate arising in the media between source and detector from Compton-scattered photons can be accounted for with a build-up factor, $B_{i}$ Refs. $[30,31] . B_{i}$ depends on the average distance a photon travels in an absorber between interactions. For short distances of the mean free path, $B_{i}$ is approximately 1 . For a thick slab absorber, the buildup factor can be approximated by the thickness of the absorber measured in units of mean free path of the incident gamma-ray. The mean free path is defined as the average distance traveled by a gamma-ray before an interaction takes place with the absorbing material. In this case, the mean free path is determined to be equal to $1 / \mu$, where $\mu$ is the linear attenuation coefficient. If the build-up factor $B_{i}$ needs to be accounted for, then the exposure rate can be expressed as:

$$
\dot{X}_{\delta}=\frac{114.1 A}{4 \pi r^{2}} \sum_{i} B_{i} P_{i} E_{i} \frac{\mu_{e n}\left(E_{i}\right)}{\rho_{\text {air }}} \exp \left[-\sum_{j} \frac{\mu_{j}\left(E_{i}\right)}{\rho_{j}} z_{j} \rho_{j}\right] \exp \left[-\frac{\mu_{\text {air }}\left(E_{i}\right)}{\rho_{\text {air }}} r \rho_{\text {air }}\right]
$$

In this way a calibration factor can be obtained for each gamma-ray energy by comparing the calculated exposure rate value to that measured by the instrument. Annex A shows an example.

Table 2: Values of the mass energy-transfer, mass energy-absorption, and mass attenuation coefficients for air. The $18 \mathrm{~K}$ in the table refers to the photoelectric absorption $\mathrm{K}$ edge.

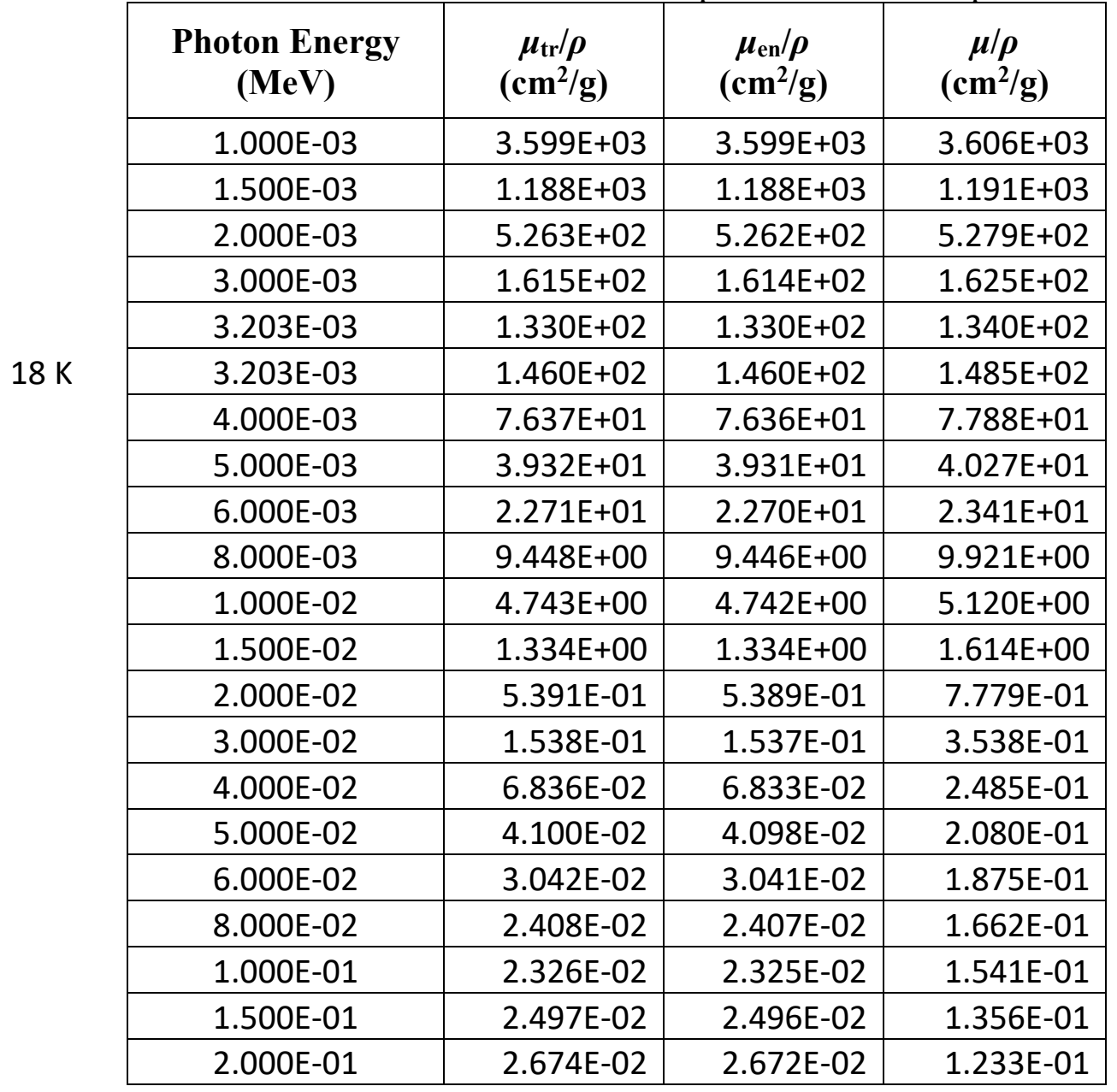




\begin{tabular}{|c|c|c|c|}
\hline $\begin{array}{c}\text { Photon Energy } \\
(\mathbf{M e V})\end{array}$ & $\begin{array}{c}\boldsymbol{\mu}_{\mathrm{tr}} / \boldsymbol{\rho} \\
\left(\mathbf{c m}^{2} / \mathbf{g}\right)\end{array}$ & $\begin{array}{c}\boldsymbol{\mu}_{\text {en }} / \boldsymbol{\rho} \\
\left(\mathbf{c m}^{\mathbf{2}} / \mathbf{g}\right)\end{array}$ & $\begin{array}{c}\boldsymbol{\mu} / \boldsymbol{\rho} \\
\left(\mathbf{c m}^{2} / \mathbf{g}\right)\end{array}$ \\
\hline $3.000 \mathrm{E}-01$ & $2.875 \mathrm{E}-02$ & $2.872 \mathrm{E}-02$ & $1.067 \mathrm{E}-01$ \\
\hline $4.000 \mathrm{E}-01$ & $2.953 \mathrm{E}-02$ & $2.949 \mathrm{E}-02$ & $9.549 \mathrm{E}-02$ \\
\hline $5.000 \mathrm{E}-01$ & $2.971 \mathrm{E}-02$ & $2.966 \mathrm{E}-02$ & $8.712 \mathrm{E}-02$ \\
\hline $6.000 \mathrm{E}-01$ & $2.958 \mathrm{E}-02$ & $2.953 \mathrm{E}-02$ & $8.055 \mathrm{E}-02$ \\
\hline $8.000 \mathrm{E}-01$ & $2.889 \mathrm{E}-02$ & $2.882 \mathrm{E}-02$ & $7.074 \mathrm{E}-02$ \\
\hline $1.000 \mathrm{E}+00$ & $2.797 \mathrm{E}-02$ & $2.789 \mathrm{E}-02$ & $6.358 \mathrm{E}-02$ \\
\hline $1.250 \mathrm{E}+00$ & $2.675 \mathrm{E}-02$ & $2.666 \mathrm{E}-02$ & $5.687 \mathrm{E}-02$ \\
\hline $1.500 \mathrm{E}+00$ & $2.557 \mathrm{E}-02$ & $2.547 \mathrm{E}-02$ & $5.175 \mathrm{E}-02$ \\
\hline $2.000 \mathrm{E}+00$ & $2.359 \mathrm{E}-02$ & $2.345 \mathrm{E}-02$ & $4.447 \mathrm{E}-02$ \\
\hline $3.000 \mathrm{E}+00$ & $2.076 \mathrm{E}-02$ & $2.057 \mathrm{E}-02$ & $3.581 \mathrm{E}-02$ \\
\hline $4.000 \mathrm{E}+00$ & $1.894 \mathrm{E}-02$ & $1.870 \mathrm{E}-02$ & $3.079 \mathrm{E}-02$ \\
\hline $5.000 \mathrm{E}+00$ & $1.770 \mathrm{E}-02$ & $1.740 \mathrm{E}-02$ & $2.751 \mathrm{E}-02$ \\
\hline $6.000 \mathrm{E}+00$ & $1.683 \mathrm{E}-02$ & $1.647 \mathrm{E}-02$ & $2.522 \mathrm{E}-02$ \\
\hline $8.000 \mathrm{E}+00$ & $1.571 \mathrm{E}-02$ & $1.525 \mathrm{E}-02$ & $2.225 \mathrm{E}-02$ \\
\hline $1.000 \mathrm{E}+01$ & $1.506 \mathrm{E}-02$ & $1.450 \mathrm{E}-02$ & $2.045 \mathrm{E}-02$ \\
\hline $1.500 \mathrm{E}+01$ & $1.434 \mathrm{E}-02$ & $1.353 \mathrm{E}-02$ & $1.810 \mathrm{E}-02$ \\
\hline $2.000 \mathrm{E}+01$ & $1.415 \mathrm{E}-02$ & $1.311 \mathrm{E}-02$ & $1.705 \mathrm{E}-02$ \\
\hline
\end{tabular}

\section{Uncertainty calculations}

Uncertainties should be calculated for both the reference chamber calibration and the secondary chamber transfer calibration. The uncertainty components should be identified for the measurements being performed. Based on the procedures described above, the uncertainty components that could be encountered, at a minimum, are the following:

- Statistical - standard deviation of the number of readings taken by the instrument

- Positioning of instrument - uncertainty in the measured distance between the source and the instrument location

- Reference beam exposure rate - uncertainty in the value of the exposure rate produced by the reference beam

- Source activity - uncertainty of the source activity used for the characterization transfer measurements

- Decay correction - correction of source activity or exposure rate value from reference time to measurement time

- Decay correction during measurement - if the source used for the characterization transfer measurements has a short half-life (e.g., half-life up to 10 times larger than 
measurement time), then decay corrections during the measurement need to be performed and the uncertainty accounted for

- Environmental - Temperature, humidity and pressure corrections, if applicable

All relative standard uncertainty $(k=1)$ components should be expressed as a percentage and combined in quadrature to obtain the combined standard uncertainty Ref. [22]. Annex A shows an example.

When calculating the uncertainty for the calculated exposure rate, the following components need to be accounted for:

- Source activity - uncertainty of the source activity used for the characterization transfer measurements

- Decay correction - correction of source activity or exposure rate value from reference time to measurement time

- Encapsulation material surrounding the source - uncertainty of the material thickness and density

- Emission intensities - uncertainty obtained from nuclear data databases Refs. [25, 26]

- Fitting of the mass energy-transfer, mass energy-absorption, and mass attenuation coefficients for air - uncertainty when obtaining these values for a given photon or gamma-ray energy

- Uncertainty in build-up factor when applied.

\section{References}

[1] ANSI/IEEE N42.32. “American National Standard Performance Criteria for Alarming Personal Radiation Detectors Used for Homeland Security."

[2] IEC-62401. 'Radiation Protection instrumentation - Alarming personal radiation devices for detection of illicit trafficking of radioactive material."

[3] ANSI/IEEE N42.48. “American National Standard Performance Criteria for Alarming Spectroscopic Personal Radiation Detectors for Homeland Security."

[4] IEC 62618. 'Radiation Protection instrumentation - Alarming spectroscopic personal radiation devices (SPRD) for detection of illicit trafficking of radioactive material."

[5] ANSI N42.33. "American National Standard Data for Portable Radiation Detection Instrumentation for Homeland Security."

[6] IEC 62533. “'Radiation Protection Instrumentation - Highly Sensitive Hand-held Instruments for Photon Detection of Radioactive Material." 
[7] IEC 62534 " Radiation protection instrumentation - Highly sensitive hand-held instruments for neutron detection of radioactive material."

[8] ANSI/IEEE N42.34, “American National Standard Performance Criteria for Hand-Held Instruments for the Detection and Identification of Radionuclides."

[9] IEC-62327, "Radiation protection instrumentation - Hand-held instruments for the detection and identification of radionuclides and for the indication of ambient dose equivalent rate from photon radiation."

[10] ANSI/IEEE N42.53, "American National Standard Performance Criteria for Backpack Based Radiation Detection Systems used for Homeland Security."

[11] IEC 62694, "'Radiation protection instrumentation - Backpack-type radiation detector (BRD) for detection of illicit trafficking of radioactive material."

[12] ANSI/IEEE N42.43, “American National Standard Performance Criteria for Mobile and Transportable Radiation Monitors used for Homeland Security."

[13] ANSI/IEEE N42.35. "American National Standard for Evaluation and Performance of Radiation Detection Portal Monitors for Use in Homeland Security."

[14] IEC 62244, "Radiation protection instrumentation - Installed radiation monitors for the detection of radioactive and special nuclear materials at national borders."

[15] ANSI/IEEE N42.38, "American National Standard Performance Criteria for Spectroscopy-Based Portal Monitors Used for Homeland Security."

[16] IEC-62484, “'Radiation protection instrumentation - Spectroscopy-based portal monitors used for the detection and identification of illicit trafficking of radioactive material."

[17] Lamperti P. and O’Brien M. NIST Special Publications, 250-58, 2001.

[18] ISO 4037-1, X and gamma reference radiations for calibrating dosimeters and dose rate meters and for determining their responses as a function of photon energy--Part 1.: Radiation characteristics and production methods.

[19] ISO 4037-2, X and gamma reference radiation for calibrating dosemeters and doserate meters and for determining their response as a function of photon energy - Part 2:

Dosimetry for radiation protection over the energy ranges $8 \mathrm{keV}$ to $1,3 \mathrm{MeV}$ and $4 \mathrm{MeV}$ to 9 $\mathrm{MeV}$.

[20] ICRU Report 31, 1979, Average Energy Required to Produce an Ion Pair.

[21] Sallaska A.L., Pibida L., Minniti R., O’Brien M. NIST Technical Note 1916 (2016). Methods for characterizing a radiation detector for specifying radiation fields during testing against standards for homeland security applications. This publication is available from: http://dx.doi.org/10.6028/NIST.TN.1916 
[22] JCGM 100:2008 - GUM 1995 with minor corrections Evaluation of measurement data - Guide to the expression of uncertainty in measurement.

[23] Seltzer, S.M., Air-Kerma-Rate Coefficients for Selected Photon-Emitting Radionuclide Sources, National Institute of Standards and Technology publication NISTIR 7092A (2004).

[24] National Institute of Standards and Technology (NIST), 2012, XCOM: Photon Cross Sections Database, available online at http://physics.nist.gov/PhysRefData/Xcom/html/xcom1.html.

[25] LNE-LNHB, Le Laboratoire National Henri Becquerel, Table of Radionuclides, http://www.nucleide.org/DDEP_WG/DDEPdata.htm.

[26] ENSDF, Evaluated Nuclear Structure Data File, National Nuclear Data Center, Chart of Nuclides, http://www.nndc.bnl.gov/.

[27] Boutillon M., Perroche-Roux AM. Re-evaluation of the W value for electrons in dry air. Phys. Med. Biol. 32, No 2: 213-219, 1987.

[28] Tables of x-ray mass attenuation coefficients and mass energy-absorption coefficients 1 $\mathrm{keV}$ to $20 \mathrm{MeV}$ for elements $\mathrm{Z}=1$ to 92 and 48 additional substances of dosimetric interest, NISTIR 5632, J.H. Hubbell and S.M. Seltzer, May 2005, http://www,nist,gov/pml/data/xraycoef/.

[29] The physics of radiology, $4^{\text {th }}$ Edition, Publisher Charles C. Thomas, Authors: Harold Elford Johns and John Robert Cunningham (1983).

[30] Measurement and Detection of Radiation, $1^{\text {st }}$ Edition, Hemisphere Publishing Corp., Author: Nicholas Tsoulfanidis (1983).

[31] Durani L., Update to ANSI/ANS-6.4.3-1991 for low-Z and compound materials and review of particle transport theory. (2009). UNLV Theses, Dissertations, Professional Papers, and Capstones. 43. http://dx.doi.org/10.34917/1363554

[32] L. Lucas, L. Pibida, M. Unterweger, and L. Karam. Gamma-ray emitting test sources for portal monitors used for homeland security. Radiat. Protection Dosimetry, Vol. 113, pp. 108111, (2005). 


\section{Appendix A: Example on how to apply the calculations and comparison with measurements}

\section{A.1 Exposure rate measurements using characterized ionization chamber}

Measurements and calculations were performed to determine the exposure rate produced by a set of sources for the following radionuclides: ${ }^{133} \mathrm{Ba},{ }^{137} \mathrm{Cs},{ }^{60} \mathrm{Co},{ }^{226} \mathrm{Ra}$ and ${ }^{232} \mathrm{U}$.

Measurements were performed using a pressurized ionization chamber for which the energy response function is shown in Fig. 1. The energy response function fit is used to determine the correction factors (CFs). The fit for the $\mathrm{CF}$ curve from $60 \mathrm{keV}$ to $211 \mathrm{keV}$ was performed using a third-degree polynomial with the following parameters:

$$
C F_{i}=10^{\left(-115.65961+159.88862 * \log 10\left(E_{i}\right)-73.29169 * \log 10\left(E_{i}\right)^{2}+11.15169 * \log 10\left(E_{i}\right)^{3}\right)}
$$

The fit for the CF curve from $211 \mathrm{keV}$ to $1292.993 \mathrm{keV}$ was performed using a second-degree polynomial with the following parameters:

$$
C F_{i}=10^{\left(0.73027-0.47257 * \log 10\left(E_{i}\right)+0.0774 * \log 10\left(E_{i}\right)^{2}\right)}
$$

The sources were placed at a distance of $1 \mathrm{~m}$ from the reference point of the pressurized ionization chamber, at a height of $1.5 \mathrm{~m}$ from the floor. The sources activities are listed in Table 3. For the multi-line radionuclide, the correction factor $(C F)$ was calculated using the weighted mean where the weighting factors were the emission intensities $\left(P_{i}\right)$ of the different gamma-rays, see Table 4. The emission intensities were obtained from LNE-LNHB, Ref. [25]. The uncertainty of the correction factors is approximately equal to $3 \%(k=1)$. The actual radiation field produced by a source is obtained by dividing the instrument reading by the correction factor. Therefore, the CF for a multi-line radionuclide was calculated as follows:

$$
C F=\frac{\sum_{i} P_{i} \times C F_{i}}{\sum_{i} P_{i}}
$$

Table 3: Source activities used for measurements

\begin{tabular}{|c|c|c|}
\hline Radionuclide & Source number & $\begin{array}{c}\text { Activity (Bq) } \\
\text { (at measurement time) }\end{array}$ \\
\hline${ }^{133} \mathrm{Ba}$ & NG474 & $(1.93 \pm 0.05) \times 10^{6}$ \\
\hline${ }^{137} \mathrm{Cs}$ & NG493 & $(2.31 \pm 0.06) \times 10^{6}$ \\
\hline${ }^{60} \mathrm{Co}$ & LL-17-60-2 & $(9.21 \pm 0.23) \times 10^{5}$ \\
\hline${ }^{226} \mathrm{Ra}$ & LL-05-226-C & $(2.79 \pm 0.07) \times 10^{5}$ \\
\hline${ }^{232} \mathrm{U}$ & LL-06-232-10 & $(3.25 \pm 0.08) \times 10^{5}$ \\
\hline
\end{tabular}

Table 4: List of calculated correction factors

\begin{tabular}{|c|c|}
\hline Radionuclide & $\begin{array}{c}\text { Correction factor } \\
\text { weighted mean }\end{array}$ \\
\hline${ }^{133} \mathrm{Ba}$ & 1.073 \\
\hline
\end{tabular}




\begin{tabular}{|c|c|}
\hline${ }^{137} \mathrm{Cs}$ & 1.031 \\
\hline${ }^{60} \mathrm{Co}$ & 1.021 \\
\hline${ }^{226} \mathrm{Ra}$ & 1.025 \\
\hline${ }^{232} \mathrm{U}$ & 1.057 \\
\hline
\end{tabular}

The measured and calculated exposure rates using Eq. 8 are listed in Table 5 and Table 6, respectively, and plotted in Fig. 2 and Fig. 4. The sources were measured both bare and shielded using an $8.7 \mathrm{~cm}$ thick polymethyl methacrylate (PMMA) container. The sources are encapsulated in a 316 stainless steel disk with a $0.025 \mathrm{~cm}$ wall thickness Ref. [32]. The measured values were corrected using the factors listed in Table 4, and the corresponding corrected values are also listed in Table 5 and Table 6 . The difference between the measured and calculated values varied between $8 \%$ and $22 \%$ (see Table 7 ).

Table 5: List of measured and corrected exposure rate values. The correction factors are listed in Table 4 Uncertainties are $\mathrm{k}=1$

\begin{tabular}{|l|l|c|c|c|c|}
\hline Radionuclide & Geometry & $\begin{array}{c}\text { Measured } \\
\text { Exposure } \\
\text { rate }(\mathbf{m R} / \mathbf{h})\end{array}$ & $\begin{array}{c}\text { Std dev } \\
\mathbf{( \% )}\end{array}$ & $\begin{array}{c}\text { Corrected } \\
\text { Exposure rate } \\
\mathbf{( m R / h )}\end{array}$ & $\begin{array}{c}\text { Uncertainty } \\
\mathbf{( \% )}\end{array}$ \\
\hline${ }^{133} \mathrm{Ba}$ & Bare & $1.335 \times 10^{-2}$ & 0.38 & $1.244 \times 10^{-2}$ & 20 \\
\hline${ }^{137} \mathrm{Cs}$ & Bare & $2.258 \times 10^{-2}$ & 0.47 & $2.190 \times 10^{-2}$ & 20 \\
\hline${ }^{60} \mathrm{Co}$ & Bare & $3.507 \times 10^{-2}$ & 0.40 & $3.434 \times 10^{-2}$ & 20 \\
\hline${ }^{226} \mathrm{Ra}$ & Bare & $7.153 \times 10^{-2}$ & 0.75 & $6.977 \times 10^{-3}$ & 20 \\
\hline${ }^{232} \mathrm{U}$ & Bare & $6.902 \times 10^{-3}$ & 0.30 & $6.531 \times 10^{-2}$ & 20 \\
\hline${ }^{133} \mathrm{Ba}$ & $8.7 \mathrm{~cm}$ PMMA & $9.478 \times 10^{-3}$ & 0.55 & $8.830 \times 10^{-3}$ & 20 \\
\hline${ }^{137} \mathrm{Cs}$ & $8.7 \mathrm{~cm}$ PMMA & $1.701 \times 10^{-2}$ & 0.39 & $1.651 \times 10^{-2}$ & 20 \\
\hline${ }^{60} \mathrm{Co}$ & $8.7 \mathrm{~cm}$ PMMA & $2.739 \times 10^{-2}$ & 0.46 & $2.682 \times 10^{-2}$ & 20 \\
\hline${ }^{226} \mathrm{Ra}$ & $8.7 \mathrm{~cm}$ PMMA & $5.609 \times 10^{-3}$ & 0.87 & $5.471 \times 10^{-3}$ & 20 \\
\hline${ }^{232} \mathrm{U}$ & $8.7 \mathrm{~cm}$ PMMA & $5.457 \times 10^{-2}$ & 0.35 & $5.164 \times 10^{-2}$ & 20 \\
\hline
\end{tabular}




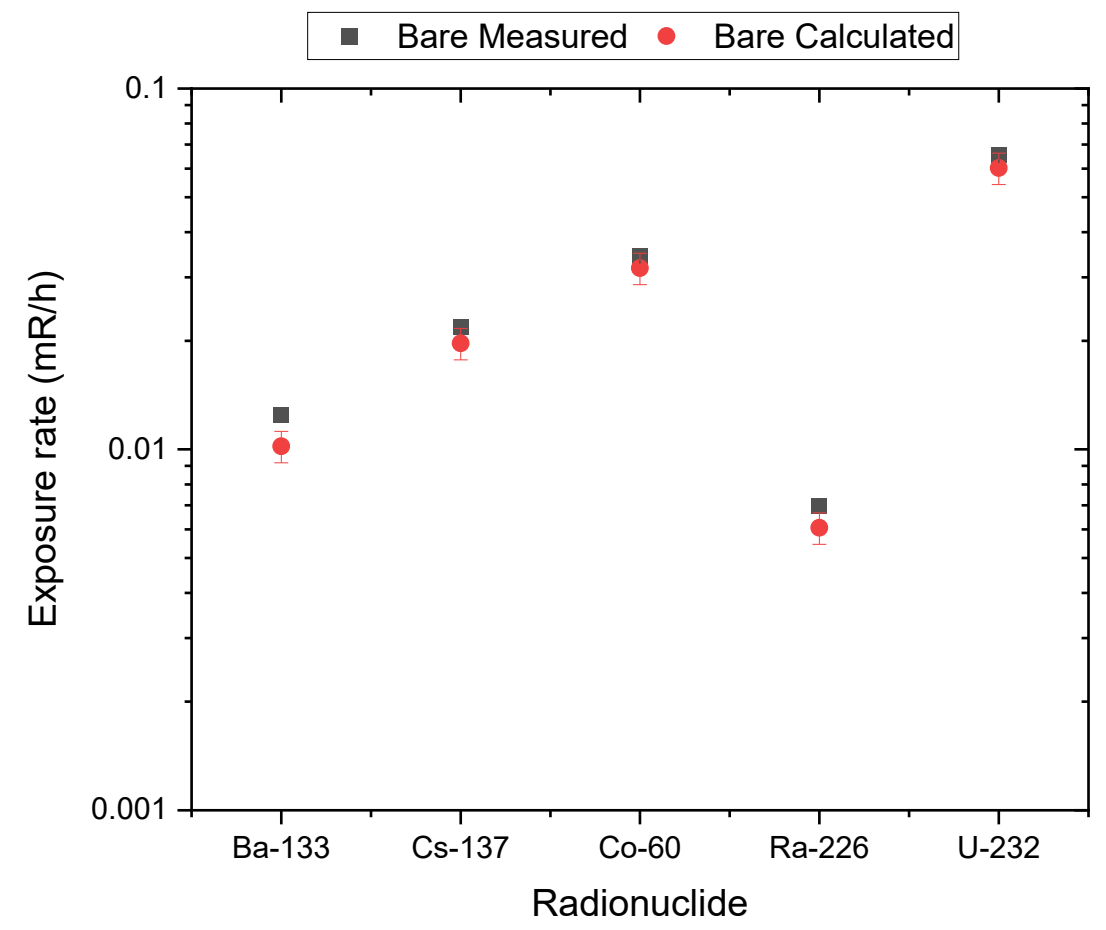

Fig. 2: Measured and calculated exposure rate values for bare sources from Table 4 and Table 5.

\section{A.2 Buildup factor from measurements and calculations}

The exposure rates produced by these sources were calculated using Eqs. 8 and 9, see Table 6. The difference between these two equations is the buildup factor in the PMMA. The buildup factors used to determine the corrected exposure rate values (listed in Table 6) were obtained from Ref. [31]. In this reference the values are provided for water and not for PMMA, so the water values are used here. If the observed differences between the calculated and measured exposure rate values can be attributed to the buildup factor, then a buildup factor can be estimated from the measurements when adding the PMMA shielding, see Table 7. For a thick slab absorber, the buildup factor can be approximated by the thickness of the absorber measured in units of mean free path of the incident gamma-ray, see Table 7 . The mean free path is defined as the average distance traveled by a gamma-ray before an interaction takes place with the absorbing material. The mean free path is determined to be equal to $1 / \mu$, where $\mu$ is the linear attenuation coefficient. The buildup factors listed in Table 7 are calculated from the mean free path weighted mean for the applicable gamma-rays emitted by the radionuclide. Fig. 3 summarizes the buildup factors listed in Table 6 and Table 7. 
Table 6: List of calculated exposure rate values. Uncertainties are $\mathrm{k}=1$.

\begin{tabular}{|l|l|c|c|c|c|}
\hline Radionuclide & $\begin{array}{l}\text { Measurement } \\
\text { Geometry }\end{array}$ & $\begin{array}{c}\text { Calculated } \\
\text { Exposure } \\
\text { rate } \mathbf{( m R / h )}\end{array}$ & $\begin{array}{c}\text { Buildup } \\
\text { factor } \\
\text { for } \\
\text { water }\end{array}$ & $\begin{array}{c}\text { Corrected } \\
\text { Exposure } \\
\text { rate* }(\mathbf{m R} / \mathbf{h})\end{array}$ & $\begin{array}{c}\text { Uncertainty } \\
\mathbf{( \% )}\end{array}$ \\
\hline${ }^{133} \mathrm{Ba}$ & Bare & $1.020 \times 10^{-2}$ & NA & NA & 20 \\
\hline${ }^{137} \mathrm{Cs}$ & Bare & $1.968 \times 10^{-2}$ & NA & NA & 20 \\
\hline${ }^{60} \mathrm{Co}$ & Bare & $3.181 \times 10^{-2}$ & NA & NA & 20 \\
\hline${ }^{226} \mathrm{Ra}$ & Bare & $6.066 \times 10^{-3}$ & NA & NA & 20 \\
\hline${ }^{232} \mathrm{U}$ & Bare & $6.022 \times 10^{-2}$ & NA & NA & 20 \\
\hline${ }^{133} \mathrm{Ba}$ & $8.7 \mathrm{~cm}$ PMMA & $3.109 \times 10^{-3}$ & 3.09 & $9.608 \times 10^{-3}$ & 40 \\
\hline${ }^{137} \mathrm{Cs}$ & $8.7 \mathrm{~cm}$ PMMA & $8.486 \times 10^{-2}$ & 2.52 & $2.138 \times 10^{-2}$ & 40 \\
\hline${ }^{60} \mathrm{Co}$ & $8.7 \mathrm{~cm}$ PMMA & $1.669 \times 10^{-2}$ & 2.05 & $3.421 \times 10^{-2}$ & 40 \\
\hline${ }^{226} \mathrm{Ra}$ & $8.7 \mathrm{~cm}$ PMMA & $2.951 \times 10^{-3}$ & 2.52 & $7.437 \times 10^{-3}$ & 40 \\
\hline${ }^{232} \mathrm{U}$ & $8.7 \mathrm{~cm}$ PMMA & $3.208 \times 10^{-2}$ & 2.52 & $8.084 \times 10^{-2}$ & 40 \\
\hline${ }^{*} \mathrm{The} \mathrm{values} \mathrm{are} \mathrm{corrected} \mathrm{by} \mathrm{the} \mathrm{buildup} \mathrm{factor}$ & & \\
\hline
\end{tabular}

Table 7: Percent differences of the measured exposure rate values to the calculated values. Uncertainties are $\mathrm{k}=1$.

\begin{tabular}{|c|c|c|c|c|c|}
\hline Radionuclide & Geometry & $\begin{array}{c}\text { Percent } \\
\text { Difference } \\
(\%)\end{array}$ & $\begin{array}{c}\text { Buildup } \\
\text { factor } \\
\text { Estimated* }\end{array}$ & $\begin{array}{c}\text { Buildup } \\
\text { factor } \\
\text { calculated } \dagger\end{array}$ & $\begin{array}{c}\text { Uncertainty } \\
(\%)\end{array}$ \\
\hline${ }^{133} \mathrm{Ba}$ & Bare & 21.9 & NA & NA & NA \\
\hline${ }^{137} \mathrm{Cs}$ & Bare & 11.3 & NA & NA & NA \\
\hline${ }^{60} \mathrm{Co}$ & Bare & 8.0 & NA & NA & NA \\
\hline${ }^{226} \mathrm{Ra}$ & Bare & 15.0 & NA & NA & NA \\
\hline${ }^{232} \mathrm{U}$ & Bare & 8.5 & NA & NA & NA \\
\hline${ }^{133} \mathrm{Ba}$ & $8.7 \mathrm{~cm}$ PMMA & -8.1 & 2.84 & 1.33 & 30 \\
\hline${ }^{137} \mathrm{Cs}$ & $8.7 \mathrm{~cm}$ PMMA & -22.8 & 1.95 & 1 & 30 \\
\hline${ }^{60} \mathrm{Co}$ & $8.7 \mathrm{~cm}$ PMMA & -21.6 & 1.61 & 1 & 30 \\
\hline${ }^{226} \mathrm{Ra}$ & $8.7 \mathrm{~cm}$ PMMA & -26.4 & 1.85 & 1.22 & 30 \\
\hline${ }^{232} \mathrm{U}$ & $8.7 \mathrm{~cm}$ PMMA & -36.1 & 1.61 & 1.35 & 30 \\
\hline
\end{tabular}




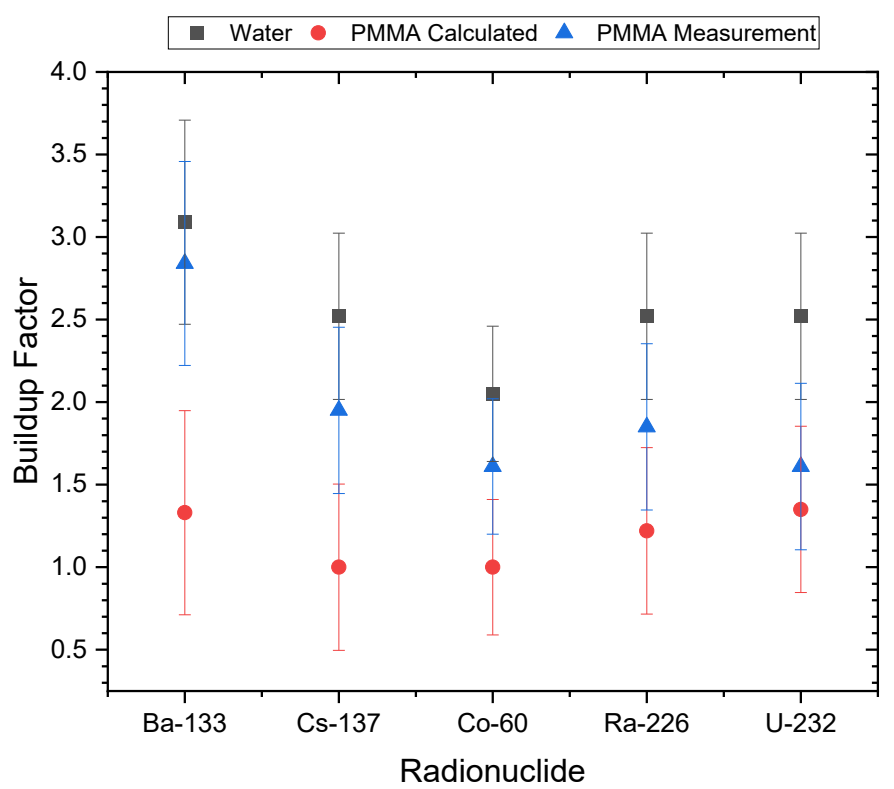

Fig. 3: Measured and calculated buildup factors. The black squares are the values obtained from Ref. [31] for water, the red circles are the calculated values for the sources surrounded by PMMA using the mean free path approximation and the blue triangles are measured values when surrounded by the PMMA shielding.

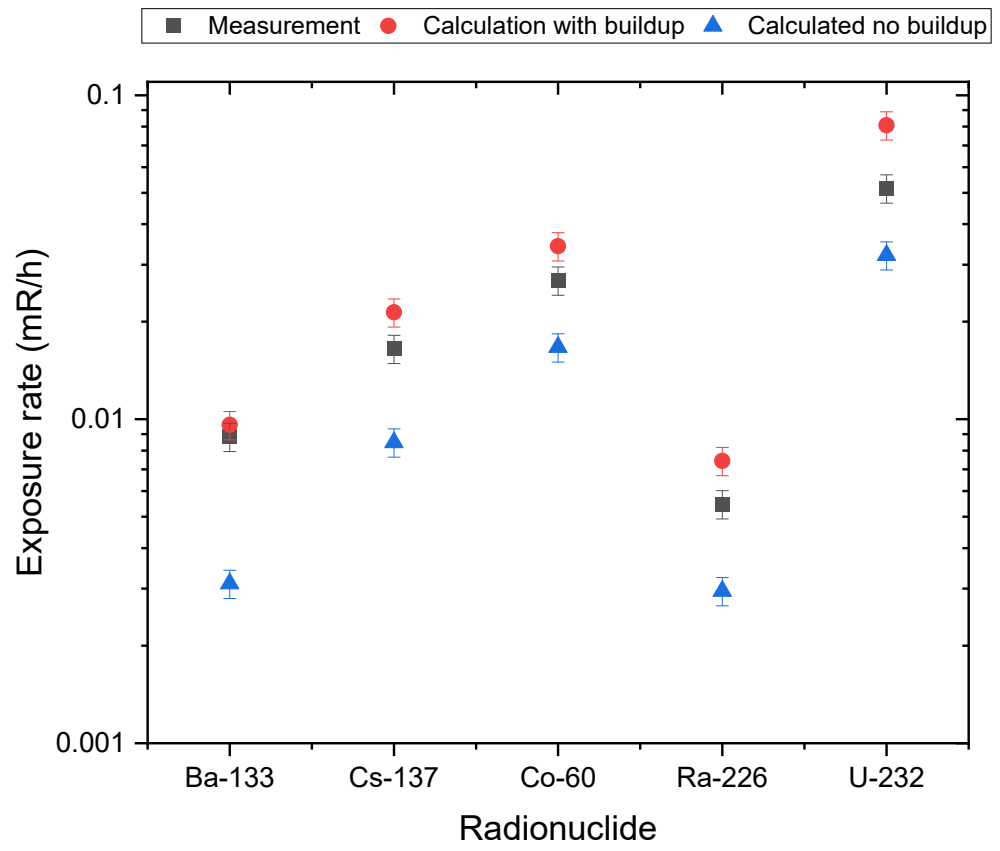

Fig. 4: The measured and calculated exposure rate values when shielded using PMMA. The black squares represent the measured values, the red circles are the calculated values corrected using the buildup factors in Ref. [31] and the blue triangles are the calculated values without applying the buildup factors. 
The differences between the calculated and the measured exposure rates for the bare sources are less than $22 \%$. The main issue with the buildup factor measured values is the correction factor used for the instrument response. There are several factors that can contribute to the differences and may include:

- the calibration of the detector using parallel beams at large distances compared to point sources at shorter distances,

- calibration is performed using mono-energetic beams while many sources emit multiple gamma-rays of different energies,

- use of the mean gamma-ray energy vs. weighted mean to determine the correction factor.

When performing instrument testing using some of the published ANSI N42 (IEEE) standards for homeland security, the radiation field required to perform a test is based on the exposure rate produced by a source when it is bare or shielded by PMMA. The radionuclides that require PMMA shielding in the standards are: ${ }^{67} \mathrm{Ga},{ }^{99 \mathrm{~m}} \mathrm{Tc},{ }^{131} \mathrm{I}$ and ${ }^{201} \mathrm{Tl}$. For these radionuclides, the buildup factor based on the radionuclide's mean gamma-ray energy is calculated using the thickness of the absorber measured in units of mean free path, see Table 8 . The buildup factors include only the mean free paths of the gamma-rays that are smaller than the size of the absorber.

Table 8: Calculated buildup factors for medical radionuclides in $8 \mathrm{~cm}$ of PMMA. Uncertainties are $\mathrm{k}=1$.

\begin{tabular}{|l|l|c|c|}
\hline Radionuclide & \multicolumn{1}{|c|}{ Geometry } & $\begin{array}{c}\text { Build- } \\
\text { up } \\
\text { factor }\end{array}$ & $\begin{array}{c}\text { Uncertainty } \\
(\%)\end{array}$ \\
\hline${ }^{67} \mathrm{Ga}$ & $8 \mathrm{~cm}$ PMMA & 1.16 & 30 \\
\hline${ }^{99 \mathrm{~m}} \mathrm{Tc}$ & $8 \mathrm{~cm}$ PMMA & 1.55 & 30 \\
\hline${ }^{131} \mathrm{I}$ & $8 \mathrm{~cm}$ PMMA & 1.50 & 30 \\
\hline${ }^{201} \mathrm{Tl}$ & $8 \mathrm{~cm}$ PMMA & 1.75 & 30 \\
\hline
\end{tabular}

\section{A.3 Calibration transfer measurements}

During the RIID test at Argon National Laboratory (ANL) in 2021, the calculated exposure rate values using Eq. 8 for bare sources were compared with the ANL measured values using the correction factors for the NIST instrument for the normalization test (NT) sources listed in Table 9. In addition, the exposure rate produced by NT sources (except for the ${ }^{232} \mathrm{U}$ ) were measured both at NIST and ANL using the respective instruments, allowing determination of the transfer correction factor using Eq. 3 .

Table 9: List of NIST instrument correction factors, the correction factors provided in instrument manual for ANL instrument and the transfer values using Eq. 3.

\begin{tabular}{|c|c|c|c|}
\hline Radionuclide & $\begin{array}{c}\text { Correction Factor for } \\
\text { NIST Instrument }\end{array}$ & $\begin{array}{c}\text { Correction Factor for } \\
\text { ANL Instrument } \\
\text { Manual }\end{array}$ & $\begin{array}{c}\text { Correction Factor } \\
\text { for ANL } \\
\text { Instrument - } \\
\text { Transfer }\end{array}$ \\
\hline${ }^{60} \mathrm{Co}$ & 1.02123 & 0.980 & 1.0393 \\
\hline
\end{tabular}




\begin{tabular}{|c|c|c|c|}
\hline${ }^{137} \mathrm{Cs}$ & 1.03071 & 1.002 & 1.0219 \\
\hline${ }^{232} \mathrm{U}$ & 1.02555 & NA & NA \\
\hline${ }^{241} \mathrm{Am}$ & 0.40578 & 0.507 & 0.5592 \\
\hline
\end{tabular}

NOTE: The instrument reading should be divided by the correction factor to obtain the radiation field produced by the sources.

The measured and calculated exposure rate values are listed in Table 10. Measurements of the small exposure rate produced by the ${ }^{241} \mathrm{Am}$ source (values are close to background levels) show a large difference and carry a large uncertainty. Within the tolerance specified in the standards, the transferred corrections can be used for sources producing exposure rates approximately 5 times background or higher. Larger uncertainties will result from low exposure rate radiation fields.

Table 10: Exposure rate calculated using Eq. 8, measured using NIST and ANL instruments for NT sources. The uncertainties for these values are approximately equal to $20 \%$.

\begin{tabular}{|c|c|c|c|c|c|c|}
\hline Radionuclide & $\begin{array}{c}\text { Calculated } \\
\text { exposure } \\
\text { rate } \\
(\mu R / h)\end{array}$ & $\begin{array}{c}\text { Measured } \\
\text { net } \\
\text { exposure } \\
\text { rate } \\
\text { without } \\
\text { correction } \\
(\mu \mathrm{R} / \mathrm{h})\end{array}$ & $\begin{array}{c}\text { Measured } \\
\text { exposure } \\
\text { rate } \\
\text { corrected } \\
\text { using } \\
\text { NIST } \\
\text { correction } \\
\text { factor } \\
(\mu \mathrm{R} / \mathrm{h})\end{array}$ & 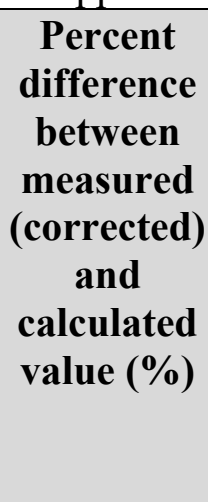 & $\begin{array}{l}\text { Measured } \\
\text { exposure } \\
\text { rate } \\
\text { corrected } \\
\text { using } \\
\text { transfer } \\
\text { correction } \\
\text { factor } \\
(\mu \mathrm{R} / \mathrm{h})\end{array}$ & $\begin{array}{c}\text { Percent } \\
\text { difference } \\
\text { between } \\
\text { transfer } \\
\text { and } \\
\text { calculated } \\
\text { value }(\%)\end{array}$ \\
\hline${ }^{60} \mathrm{Co}$ & 65.56 & 66.67 & 65.28 & -0.42 & 64.15 & -2.2 \\
\hline${ }^{137} \mathrm{Cs}$ & 25.59 & 27.50 & 26.68 & 4.27 & 26.91 & 5.2 \\
\hline${ }^{232} \mathrm{U}$ & 79.82 & 93.04 & 90.73 & 12.7 & NA & NA \\
\hline${ }^{241} \mathrm{Am}$ & 1.635 & 0.646 & 1.549 & 1.64 & 1.124 & -31 \\
\hline
\end{tabular}

NOTE: The instrument readings were divided by the correction factor to obtain the radiation field produced by the sources. 